\title{
Primary percutaneous coronary intervention with drug-eluting stent in patient presenting with acute inferior myocardial infarction with dextrocardia
}

\author{
Erdem Özel ${ }^{\mathrm{a}, *}$, Ömer Şenarslan ${ }^{\mathrm{b}}$, Dilşad Amanvermez Şenarslan ${ }^{\mathrm{c}}$, Samet Uyar ${ }^{\mathrm{b}}$, Ali Özturk ${ }^{\mathrm{b}}$, \\ Emin Evren Özcan ${ }^{\mathrm{b}}$, Ahmet Taştan ${ }^{\mathrm{b}}$, Talat Tavlı ${ }^{\mathrm{b}}$ \\ a Tepecik Education and Research Hospital, Department of Cardiology, Izmir, Turkey \\ b Sifa University, School of Medicine, Department of Cardiology, Izmir, Turkey \\ c Celal Bayar University, School of Medicine, Department of Cardiovascular Surgery, Manisa, Turkey
}

\section{A R T I C L E I N F O}

\section{Article history:}

Received 17 June 2015

Accepted 29 July 2015

Available online 3 September 2015

\section{Keywords:}

Dextrocardia

Acute myocardial infarction

Drug eluting stent

\begin{abstract}
A B S T R A C T
Dextrocardia is a very rare congenital cardiac disorder in a normal population. A 62-year-old male patient was admitted to our center with a right chest pain. On admission, patient informed us that he had dextrocardia. On his electrocardiography, there was a $2 \mathrm{~mm}$ ST elevation on D2-D3-AVF and reciprocal ST depression on V1-4. On coronary angiography, RCA was totally occluded from proximal portion after giving SA nodal artery. We have successfully treated him with primary PCI by implantation DES and then electively PTCA to OM lesion. (c) 2015 The Society of Cardiovascular Academy. Production and hosting by Elsevier B.V. All rights reserved. This is an open access article under the CC BY-NC-ND license (http://creativecommons.org/licenses/by-nc-nd/4.0/).
\end{abstract}

\section{Introduction}

Dextrocardia is a very rare congenital cardiac disorder in normal population. It could be with complete transposition of abdominal organs (situs inversus totalis) or solely. Incidence of coronary artery disease with dextrocardia is not different from normal population. ${ }^{1}$ Coronary angiography, elective coronary interventions and coronary artery bypass surgery have been reported on this condition, but primary percutaneous coronary intervention $(\mathrm{PCI})$ in a dextrocardia patient has been rarely reported probably due to the rarity of this condition. Apart from standard procedures, some special technical aspects should be considered in the percutaneous coronary angioplasty of these patients, such as the opposite direction of manipulation of the catheters. In this report, we will discuss a patient with dextrocardia who came to our center with acute inferior myocardial infarction and was successfully treated with drug-eluting stent (DES) implantation and then electively PTCA to OM lesion.

\section{Case}

A 62-year-old male patient was admitted to our center with a right chest pain which radiates to the right arm. His pain started $30 \mathrm{~min}$

\footnotetext{
* Corresponding author. Tel.: +90232343 44 45; fax: +90 2323435656 .

E-mail addresses: erdem.ozel@hotmail.com (E. Özel), dromersen@yahoo.com (Ö. Senarslan), sametuyar@hotmail.com (S. Uyar), alinihil@gmail.com (A. Özturk), eeozcan@hotmail.com (E.E. Özcan), ahmettastan@turk.net (A. Taştan), talat.tavli@sifa.edu.tr (T. Tavlı).

Peer review under responsibility of The Society of Cardiovascular Academy.
}

ago. On admission, patient informed us that he had dextrocardia. Hypertension and new diagnosed diabetes mellitus are risk factors for coronary artery disease. On his electrocardiography, there was a $2 \mathrm{~mm}$ ST elevation on D2-D3-AVF and reciprocal ST depression on V1-4 (Fig. 1). His blood pressure was $110 / 75 \mathrm{mmHg}$ with $117 / \mathrm{min}$ heartbeat. On physical examination, there was no abnormality except dextrocardia and situs inversus. Acute inferior wall myocardial infarction was diagnosed and $300 \mathrm{mg}$ ASA, $300 \mathrm{mg}$ clopidogrel and 5000 IU IV heparin bolus were administered, and he was transferred to the catheterization laboratory for performing primary $\mathrm{PCI}$.

Cardiac catheterization was performed via the right common femoral artery, using a $7 \mathrm{Fr}$ introducer. We used mirror-image coronary angiography angulations for the procedure. His thoracic aorta was lying right to the sternum. Cannulation of left main coronary artery (LMCA) was achieved by a 7 Fr Judkins left (4.0) catheter without difficulty. Right coronary artery (RCA) was cannulated with a 7 Fr Judkins right (4.0) guiding catheter with slight clockwise rotation and pulling. On coronary angiography, left anterior descending artery was normal and there was an $80 \%$ critical lesion in the mid part of the first optus margin (OM) branch. RCA was totally occluded from proximal portion after branch of the sinoatrial node artery (Fig. 2). So, urgent PCI to RCA was decided. Total occlusion was crossed by a 0.014 " hi-torque BMW guide-wire (Abbott Laboratories, Abbott Park, IL, USA) and balloon dilatation was performed with $2.0 \times 20 \mathrm{~mm}$ Maverick balloon (Boston Scientific, Boston, MA, USA). After balloon dilatation, distal flow was achieved. Because of re-coil, $2.75 \times 28 \mathrm{~mm}$ Xience-V stent (Abbott Laboratories, Abbott Park, IL, USA) implanted to the lesion at $10 \mathrm{~atm}$ (Fig. 3). After stent implantation, distal antegrade TIMI-3 flow was achieved 


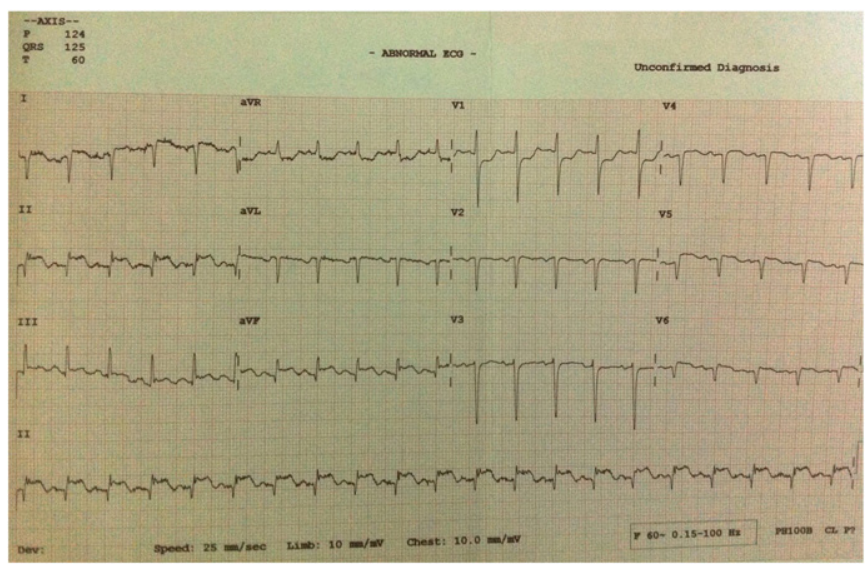

Fig. 1. ECG of standard limb and chest leads to suggestive dextrocardia and inferior wall myocardial infarction.

without residual stenosis and complication. Intervention to OM lesion was planned in a second procedure. The patient was counseled to receive dual anti-platelet therapy with aspirin and clopidogrel for at least one year, as well as an angiotensin-converting enzyme inhibitor, a beta-blocker and a statin.

\section{Discussion}

Situs inversus with dextrocardia is a rare congenital anomaly with an incidence of 1 per 10,000 individuals. Incidence of coronary artery disease in these groups is similar with the normal population. ${ }^{1}$ The pathogenesis of origin is in the embryonic stage of development, where a defect in the folding of the primitive heart tube results in malposition of the cardiac apex into the right chest. ${ }^{2}$ Coronary interventions and coronary artery surgery had been reported in dextrocardia. ${ }^{3-5}$ There may be some problems while performing coronary intervention in this special population. While performing angiography, mirrorimages of standard angiographic views have to be used. Also opposite of standard maneuvers has to be used for cannulation and engagement. ${ }^{6}$ In 2005 double-inversion technique described by Goel PK. and this technique normalizes all angiographic views to the standard conventional views as seen in a normally located heart and makes interpretation easy and avoids interpretive errors. ${ }^{7}$ As previously mentioned,

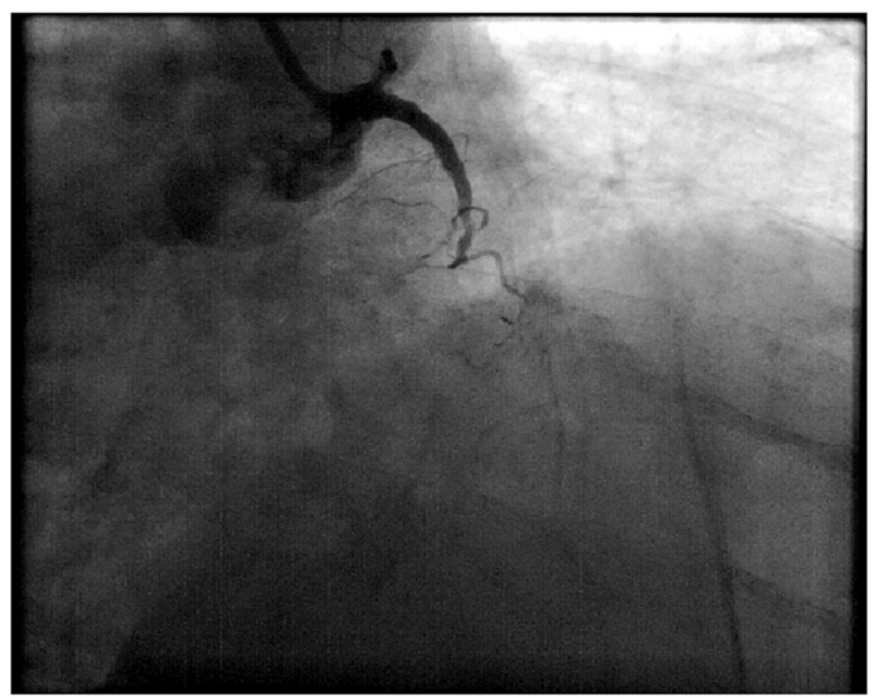

Fig. 2. Right coronary artery (RCA) injection in right anterior oblique view $\left(25^{\circ}\right)$ showing total cutoff of the mid RCA

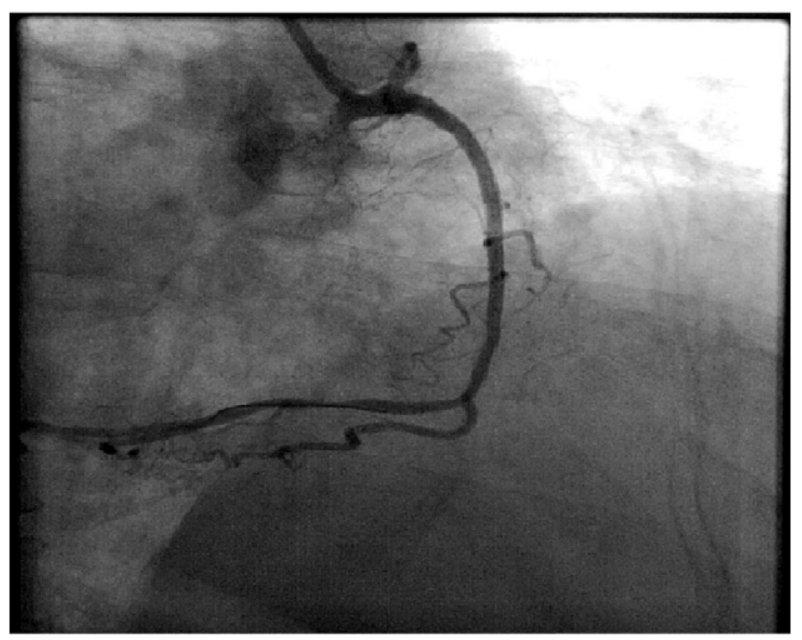

Fig. 3. Post angioplasty right coronary artery (RCA) injection in right anterior oblique view $\left(25^{\circ}\right)$ showing normally flowing vessel.

RCA cannulation could be more challenging than LMCA cannulation. Also in our case, we cannulated the LMCA with standard left Judkins without difficulty, but cannulation of RCA with standard right Judkins was achieved after a few failed attempts. All the previous reports offered counter-clockwise rotation for cannulation of RCA. ${ }^{3,4}$ In contrast to previous reports, we could engage the right catheter with slight clockwise rotation and pull-back maneuver. In our case, right Judkins catheter provides enough support for delivering the equipment. In conclusion; we report a rare case of acute myocardial infarction in a case of situs inversus with dextrocardia and successfully treated by DES implantation in primary $\mathrm{PCI}$.

\section{Declaration of conflicting interests}

The author(s) declared no conflicts of interest with respect to the authorship and/or publication of this article.

\section{Funding}

The authors received no financial support for the research and/or authorship of this article.

\section{References}

1. Dubb A, Schamroth L. Dextrocardia with myocardial infarction. Chest 1985;88(1): $119-120$.

2. Freed MD, Plauth JrWH. The pathology, pathophysiology, recognition and treatment of congenital heart disease. Hurst's the Heart. 9th ed. McGraw-Hill; 1998. p. 1925-1993.

3. Jauhar R, et al. Primary angioplasty in a patient with dextrocardia. J Interv Cardiol 2005;18(2):127-130.

4. Zambrano J, De la Hera A, De Marchena E. Mechanical reperfusion during acute myocardial infarction in a patient with dextrocardia. J Invasive Cardiol 2006;18(2): E89-E92.

5. Irvin RG, Ballenger JF. Coronary artery bypass surgery in a patient with situs inversus. Chest 1982;81(3):380-381.

6. Macdonald JE, Gardiner R, Chauhan A. Coronary angioplasty via the radial approach in an individual with dextrocardia. Int J Cardiol 2008;131(1):e10-e11.

7. Goel PK. Double-inversion technique for coronary angiography viewing in dextrocardia. Catheter Cardiovasc Interv 2005;66(2):281-285. 